\title{
Innovation in Services: CORPORATE CULTURE AND INVESTMENT BANKING
}

\author{
Richard K. Lyons \\ Jennifer A. Chatman \\ Caneel K. Joyce
}

eaders of most service businesses find little guidance in existing writing on innovation. The central themes of R\&D, intellectual property, and breakthrough technologies often miss how service businesses evolve by steadily generating and implementing new ideas. The lack of guidance would not be puzzling if services' share in the business sector were small, or if innovation in services were unimportant. However, neither is true. In modern economies, service businesses account for most of the value created. In the U.S., for example, services now account for about 78\% of GDP; the major economies of Europe and Asia are similar in their service emphasis. ${ }^{1}$ Even the manufacturing sector, which accounts for most of the remainder, incorporates significant services in the products it creates. ${ }^{2}$

Innovation in services is important in part because it is one of the only effective ways to fight commoditization. Forces toward commoditization in services are fierce, and getting more so, as these markets become more open, more tradable, and more contested. Commoditization often occurs even faster in services than in physical products because innovations are easier to copy and there are fewer patent protections, lower front-end capital investments, and shorter product cycles. The rapid rise in global services trade, the significant liberalization in cross-border flows of services and capital, and the rapid globalization of many service firms are evidence of this trend. ${ }^{3}$ In many industries, for example, compensation for providing intermediation - the services of middlemen-has collapsed. ${ }^{4}$ Despite these distinct trends, writing on innovation remains primarily focused on physical products and high technology.

We define innovation broadly as the combination of creativity and implementation. ${ }^{5}$ Thus, we focus on both the production of novel and useful ideas that improve effectiveness as well as the methods used to put the creative ideas into practice. Innovation can include doing old things in new ways rather than 
developing completely new inventions. This includes ideas originating outside the organization that are customized to an organizational context or clientele. New ideas must be implemented-i.e., delivered to customers-to create commercial value.

Competing on service innovation requires a more intensive set of organizational practices than competing on physical product innovation. To understand these differences, we examine a particular service business-the professional service of investment banking. Though investment banking is one of many relevant service industries, it is a fine exemplar for several reasons. First, it is large: investment banks and the non-retail portion of money-center commercial banks account for significantly more market capitalization than any other "services" sector, including healthcare. ${ }^{6}$ Second, the competition is keen. For example, "league tables" that rank investment banks based on deal flow are published regularly and are taken seriously as a measure of reputation by clients and competitors alike. Third, the essential elements driving innovation in investment banking are common to other service industries, which illustrates how organizations in those industries may benefit from thinking more deliberately about innovation. Yet the means by which top firms in this industry create value through innovation is not well understood.

There are service innovation pitfalls that arise from the unconsidered application of concepts conceived in a physical product innovation context. For example, research on physical product innovation tends to focus on radical, game-changing shifts, whereas innovation in services tends to be more fluid and evolutionary, and thus top competitors are characterized more by their steady pace over time than by making gains with long-shots. New product innovation in manufacturing involves a lot more fixed investment and much greater commitment to longer production runs, making it necessary to move things more abruptly to justify those investments. Similarly, in new technology innovation, what is often at stake are new industry-wide standards and infrastructure, which tend to be more discrete.

Exploring the differences between product and service innovation illuminates the importance of fostering a "service innovation culture," which we define as the consistent, coherent, and comprehensive presence of values and norms that promote fresh thinking and swift execution in service firms. Organizational structures and processes are the building blocks of this culture, and they include formal and inforRichard K. Lyons is the Chief Learning Officer at Goldman Sachs and previously served as acting dean and Sylvan Coleman Professor of Finance at the Haas School of Business at UC Berkeley.

Jennifer A. Chatman is the Paul J. Cortese Distinguished Professor of Management at the Haas School of Business at UC Berkeley.

Caneel K. Joyce is a Ph.D. candidate at the Haas School of Business at UC Berkeley. mal incentives, socialization, role modeling, and venues for sharing information. ${ }^{7}$ The behavioral norms and values that define culture are vitally important in services, in contrast to physical products, because behavior itself is the product. 
Whether in manufacturing, technology, or services, leadership is fundamentally about steering and managing change. ${ }^{8}$ However, a systemic organizational approach to innovation in services goes beyond the core elements of leading a specific change. It anchors the competing-on-innovation vision as a process and as a culture. In this way, the systemic approach can provide more powerful strategic execution and business success in professional service firms.

\section{Case Study: Innovation in Investment Banks}

A recent survey on innovation in Business Week asserts that "innovation in services is rare." ${ }^{\prime 9}$ This claim is difficult to support in the context of investment banking. A simple thought experiment illustrates why. Take any one of several jobs in those organizations: a merger advisor, a foreign exchange trader, or a private wealth advisor. Put them to sleep ten years ago and wake them up today. They would not know how to do their jobs. The landscape in each of those lines of business has evolved tremendously, thereby fundamentally changing a job incumbent's day-to-day responsibilities. For example, financing mergers now involves many methods that did not exist ten years ago; the people who arrange this merger financing within the organization are now staffed within a different division; trading now takes place with a different set of counterparties, using a much broader array of trading methods; and the set of asset types available to investors, from private equity to exchange traded funds, have all changed dramatically, as have the associated strategies. In a nutshell, innovation in the investment banking industry has been breathtaking. There is every reason to expect that the next ten years will continue to be characterized by major changes.

However, the innovation that has occurred within the investment banking industry does not align well with the central themes in existing writing on innovation. For example, existing work focuses on innovation termed radical, disruptive, or game-changing. ${ }^{10}$ However, industry participants do not view the changes as the result of radical innovation, or even a small set of radical innovations. It is instead the culmination of hundreds of small advances each month, across many different fronts, that over time becomes transformative with "most improvements to service activities [being] incremental."11

Other central themes of existing work are not apt either. Take intellectual property: little of these firms' performance relies on intellectual property protection or the cash flows that derive from protection. Patents have little to do with the creation and diffusion of novel ideas and processes, especially when the industry is one of rapidly evolving incremental innovations ${ }^{12}$ such as investment banking. ${ }^{13}$ The theme of R\&D that so pervades existing work is also strained when applied to investment banking, at least when understood as a concentrated process with well-defined staffing, budgets, and project flow. Instead, what might be called "R\&D" within investment banks is in fact a highly distributed function that remains firmly anchored within the constituent businesses, 
rarely strays far from immediate implementation, and in fact is generally involved in implementation.

If innovation is occurring in investment banking, but differently than in the traditional engineering-centered view of innovation, then how do we understand it? We outline four fundamental enablers-client demand for services that span boundaries, broad and deep client relationships, tight integration between design and execution, and the vision of innovation articulated at the top-the constellation of which likely has greater power than their sum. Because of the competitive context of investment banking, the approach to develop and sustain organizational innovation needs to be firm-wide. This same competitive context is present in many other service businesses, including consulting, software, legal services, and accounting.

\section{Value in Boundary Spanning}

Modern investment banks are essentially collections of inter-related businesses, delineated by divisional boundaries and often within-division boundaries. The term "investment bank" comes from the traditional business of providing advice to firms that want to issue new securities, merge with another firm, or acquire a firm. ${ }^{14}$ Investment banks are now deeply involved in other distinct businesses, including securities trading for clients and their own accounts and also in the areas of investment and wealth management, each of which is typically organized as a division. Some of the biggest opportunities, and biggest potential rewards, are at the interfaces of these domains. An example is the link between providing advice for an acquisition (traditional investment banking) and providing the financing for the same deal. Financing was historically sourced from the firm's trading or securities division, but teams responsible for this work are now sometimes integrated within the investment banking division, with great advantage in terms of agility. For example, firms that can both advise a client about the acquisition and become a co-investor in the acquired entity can deepen their client's access to capital markets through this additional signal of deal quality. Firms unwilling or unable to compete in this way lose out.

Another approach to the opportunities in boundary-spanning is the "strategist" groups that banks have set up to be in close contact with a broad range of divisions and businesses. Though it is often easy to copy specific service products, it is not as easy to copy how they are provided, which often relies on underlying organizational innovations. Such innovative practices can provide advantages over sustained periods.

Exploiting these and other opportunities requires finding new solutions to both old and new problems-a significant organizational challenge. For example, some firms have repositioned a team within a different organizational unit while others have embedded a team across multiple organizational units. However, as in other professional service firms, creative thinking among only a subset of individuals within a firm is likely insufficient to fully capitalize on the opportunities for growth and change in investment banking. 


\section{Client Relationships Are Broad and Deep}

There is great interest and appreciation in the fields of marketing and new product development for the value of ethnography in understanding client needs and, importantly, anticipating how those needs are likely to change. Natalie Hanson, SAP's director for business development agrees, "Ethnography is most effective when it's used to spot breakthrough innovations. We don't use it for incremental improvements or to solve small problems. Ethnography works best when the questions are big and broad. The good time to use it is with futuristic research." ${ }^{15}$ However, while a global INSEAD/Booz-Allen study of 186 companies found that $90 \%$ felt deep customer insights played a vital role in identifying the potential for new products and services, only technology innovators-the subset of respondents that sought to be the first to market with breakthrough technologies-placed strong emphasis on uncovering these deep customer insights. ${ }^{16}$

The notion of significant interaction with one's clients is considered a best practice in investment banking, and this extends to other professional service businesses. At many investment banks, the concept of anticipating client needs is sacred. For example, one business principle at Goldman Sachs states that "we consistently strive to anticipate the rapidly changing needs of our clients." ${ }^{17}$ Responsibility for client relationship management remains broadly distributed. The model is the producer-manager, so production-understood in large part as deriving from relationships-remains the responsibility of a much larger share of employees than would be the case in physical product businesses. ${ }^{18}$ While this many-touch approach serves to protect the firm's franchise when employees depart, its contribution to innovation is less widely recognized (despite considerable evidence for the value of bringing together diverse teams to stimulate innovation). ${ }^{19}$

\section{Design and Execution Are Tightly Integrated}

Clients of investment banks want creative solutions, meaning they are looking for new and useful ideas that solve the problems that are important to them. Depending on the domain, these can take the form of new variations on existing financing solutions, investment solutions, or strategic solutions. Some of these solutions are focused on cost reduction. The more valuable solutions are aimed at increasing clients' strategic degrees of freedom, for example, by giving them access to investment opportunities that their size or access would not normally enable. It is most precise to think of these solutions as co-developed with clients because deep and consistent client input is the norm. ${ }^{20}$

The "total product" offered by investment banks generally involves both design and execution, with the two phases blurred. ${ }^{21}$ More specifically, the phases often iterate with the assistance of client input. These feedback loops occur naturally in the design phase and are an important driver of innovation pace. They also help explain why commoditization occurs so quickly, since clients rarely work with a single investment bank. 


\section{CEO's Articulate a Clear Vision of Innovation}

The fourth important enabler of innovation is the emphasis afforded to innovation by industry CEOs. Many articulate their vision using the concept of innovation (e.g., Goldman Sachs, UBS, and Credit Suisse First Boston). An innovation-based vision clarifies why future organizational success stems not from being the same, but from being different-purposefully different. The visions are communicated within the investment banking industry (and others) with the support of a powerful tradition of storytelling: who built what business, how, and key insights. ${ }^{22}$ Of course, the leader's tone from the top contributes to innovation in physical product industries as well, so it does not, in itself, distinguish services. However, when viewed as part of a constellation of contributors within a service industry such as investment banking, senior leaders' support becomes essential for activating the distributed responsibility for fresh thinking. In other words, they develop and support a culture of innovation.

Given the importance of culture in promoting innovation in service organizations, we turn to a discussion of the relationship between culture and innovation and some of the practices associated with a service innovation culture.

\section{Culture and Innovation Together}

Innovation research has often focused on identifying the determinants of creative potential among individuals, ${ }^{23}$ but researchers have devoted less attention to understanding sustained innovation at the group and organizational levels. Past research has identified several determinants of innovation, including leadership, cohesiveness, organizational size and structure, and resource availability. ${ }^{24}$ A critical yet less obvious source of influence on innovation is an organization's cultural norms. We define culture as a system of shared values that define what is important and norms that define appropriate attitudes and behaviors for organizational members. ${ }^{25}$ As a system of social control, organizational culture can influence members' focus of attention, behavior, and commitment. Through members' clarity about organizational objectives and their willingness to work toward these objectives, culture increases an organization's ability to attain valued goals by executing more efficiently on its strategy. ${ }^{26}$

Sustained innovation requires a cultural foundation, embedded in how people lead and are led, that permeates the organization. Put differently, creative people will not by themselves produce full-fledged, sustainable innovation in organizations. Cultural norms can be a powerful means of stimulating innovation by attaching social approval to activities that facilitate innovation. Past research has found that norms are central to characterizing how work is conducted at the organizational and group levels ${ }^{27}$ and may influence group creativity. ${ }^{28}$ Thus, successful service innovation may depend on the unique cultural norms that organizations develop and the extent to which an organization's cultural orientation aligns with, and is supported by, its overall strategic orientation. ${ }^{29}$ 


\section{The Paradox: Can a Strong Culture Encourage Innovation?}

On the face of it, a strong culture would seem to hinder innovation. Sorensen suggested that strong culture firms, while experiencing superior performance in stable businesses, may be unable to engage in exploration learning or to discover alternative routines, technologies, and purposes that would be necessary in a volatile industry. ${ }^{30}$ Many others have agreed that strong cultures can be detrimental to innovation, claiming that strong agreement, in any form, effectively stifles innovation. Nemeth and Staw, for example, have argued that as cohesion among organizational members intensifies, groups tolerate less deviation. ${ }^{31}$ Yet, it is this very deviation that provides the potential for innovation in organizations since freedom to express ideas without fear of reprisal from others increases the potential that people will express creative solutions rather than suppress them. When organizational norms are strong, people will adopt the dominant perspective and potential dissenters who may provide alternative perspectives will refrain from voicing their opinions for fear of rejection or ostracism. This tendency may be exacerbated in organizations where "one of the most significant psychological tendencies is a strain toward uniformity, a tendency for people to agree on some issue or to conform to some behavioral pattern." 32

Chatman and Flynn challenged the view that strong culture and innovation are opposing forces in organizations. ${ }^{33}$ They suggested that by distinguishing between culture strength and culture content, or between conformity and uniformity, strong cultures can fuel rather than constrain innovation. They suggested that norm strength reflects the extent to which members conform to organizational norms but not necessarily the extent to which members behave uniformly. While conformity entails bringing different people's interests into agreement or harmony, uniformity implies that a group of people is not simply in harmony, but identical to one another in terms of interests attitudes and behaviors.

A strong culture can be a powerful form of social control because it provides agreed-upon standards that members may use to assess the appropriateness of their own and others' actions or beliefs. ${ }^{34}$ However, it would be incorrect to assume that strong, cohesive organizational cultures induce identical or uniform patterns of thought and behavior among members. Cohesive organizational cultures can emphasize divergent thinking because cohesion relates to the strength of group norms rather than their content. Leaders of consistently innovative firms, like 3-M, create a culture that manages the constant tension between consistency and fresh thinking that inevitably arises, most prominently in service industries. ${ }^{35}$

\section{Developing Sustained Innovation in Service Organizations}

Innovation in service organizations is even more reliant on organizational culture than in manufacturing organizations. In service organizations, informal social control may be more important than in physical product or technology 
innovation. Without a physical product line or an identifiable technology, monitoring quality and consistency is more difficult. So innovating in service organizations requires that norms and values guide behavior to ensure quality, consistency, and reliability. For example, at Southwest Airlines, an organization that has received much attention for its strong culture, employees prioritize keeping costs low and customer service high; goals that are utterly consistent with Southwest's business strategy. ${ }^{36}$ Southwest benefits from employees who are willing to monitor their own and others' behavior, resulting in significant alignment between Southwest's strategy and employee behavior.

We identify five key distinctions between innovation in services and innovation in manufacturing. First, innovation in services is distributed throughout the organization. Second, it is fluid and continuous in pace. Third, it is far more relevant to hiring and promotion decisions. Fourth, it is influenced by formal reward systems and culture at the firm-wide level. Finally, it is strongly influenced by leaders' behavior. The foundations-both cultural and structuralfor competing on innovation in services should be pervasive.

- Innovation in services is distributed throughout the organization. What norm might emphasize cultural agreement and intensity without mandating uniformity? A norm that induces conformity but not uniformity throughout an organization is "we agree to disagree." Employees at HewlettPackard (HP), for example, strongly agree about the norms of the firm, which emphasize individual freedom and autonomy to accomplish work goals. ${ }^{37}$ To demonstrate its commitment to individual freedom, HP often provides informal rewards, such as the legendary "Medal of Defiance" to employees for instances of useful dissent. HP's organizational culture is considered strong because of the high level of agreement among employees about "how things are done around here," not because employees work in a synchronous, lock-step pattern of uniformity. ${ }^{38}$

At Google, innovation is a primary cultural norm that permeates the organization with many supporting practices. These include engineers pooling their ideas and efforts mentored by Marissa Mayer (Vice President, Search Products \& User Experience) during her university style "office hours." Ideas are taken quickly and directly to the top with founders Larry Page and Sergey Brin reviewing products directly (in white lab coats) and expecting push back. ${ }^{39}$

- Innovation in services is fluid and continuous. Current research has focused on product-based innovation, which is typically viewed as discrete. Because of the manufacturing process, physical product innovation tends to involve distinct stages of concept generation, concept development, and concept implementation. ${ }^{40}$ Each stage is an opportunity for top-down monitoring, input, and approval. Even the recent movement away from this stage gate model, toward more "extreme" product development environments, cannot achieve fluidity (processes happen iteratively, and perhaps concurrently-but not simultaneously). In contrast, in services, the creative stage is intertwined with implementation with the point of 
conception often being the point of execution. Thus, design and delivery can be concurrent, for example, when a client calls for an integration across distinct services that is immediately recognized as deliverable.

The fluidity of service innovation presents a different set of challenges entirely. Of course, the setting must be right before leaders can distribute this kind of rapid-fire decision-making authority throughout the organization. Giving employees the latitude to implement new ideas as they arise is a risk. Like most knowledge work, it demands that leaders have hired the right people, and that communication is open and fluid. However, service innovation is unique in the extent to which employees must be informed, up-to-date, and accountable for sound decision-making processes and long-term strategic objectives rather than simply for the outcomes of innovative ideas.

- Innovation in services is broadly relevant to hiring/promotions. In the largest accounting firms, hiring and promotions are based on how well a potential recruit's values fit with the firm's values. ${ }^{41}$ Because accountants spend a great deal of time with clients, these firms depend on a high level of cultural fit among their staff so that they are appropriately represented and work is done consistently with their firm's values. This substantial exposure to clients and variation in client needs requires staff to be innovative in adapting to client needs and idiosyncrasies while upholding appropriate industry and SEC standards.

Similarly, at General Electric, hiring and promotion criteria are clearly related to their innovation strategy. Required criteria for becoming a leader at GE includes being "committed to stimulating and relishing change rather than being frightened or paralyzed by it; seeing change as an opportunity, not a threat; having a passion for excellence; hating bureaucracy and all the nonsense that comes with it; having enormous energy and the ability to energize and invigorate others." 42 "Leaders at GE understand speed as a competitive advantage and see the total organizational benefits that can be derived from a focus on speed." ${ }^{43}$

- Innovation in services is enabled by leadership. Leaders are responsible for managing the inherent paradox between a strong culture and innovation. "As with other priorities, chief executives also must create a corporate culture that makes innovation everyone's goal. The CEO needs to create an atmosphere that rewards innovative approaches," says John McKenna, CEO of Siemens Business Services, a U.S. subsidiary of Siemens AG in Germany. ${ }^{44}$ "In broad terms, the CEO needs to champion the idea that innovations will generate value across the business." Under McKenna's direction, Siemens created a group called "Innovation $\delta$ Transformation." It was instrumental in developing the Customer Innovation Workshop, a series of client meetings that identify and create business value. Siemens' senior subject-matter experts work collaboratively with customers, business, and IT stakeholders to develop road maps, a desired outcome, and deliverables that show the client how to implement a particular project. 
Through the workshop, Siemens helped one client design a virtual solution to lower its support costs." ${ }^{45}$

Leaders who foster innovation also encourage debate and conflict. ${ }^{46}$ Andy Grove, the founder and former CEO of Intel, defines one of their core norms as "constructive confrontation," which entails "ferocious arguing with one another while remaining friends and is critical to the creation of new knowledge." ${ }^{47}$ Meg Whitman, CEO of eBay, describes their culture as: "At eBay, we have a 'no penalty' culture, meaning that there is no penalty for being on the wrong side of an issue or changing your mind in the face of better information. If you come to a meeting with one point of view and a colleague says something than convinces you that you're wrong, the culture is to say, 'O.K.-that's smart. You're right. Let's move on. '" ${ }^{48}$ Similarly, Veli-Pekka Niitamo, Director of Global Strategic Resourcing at Nokia, states that, "For us, teamwork isn't a vision of great harmony. We expect our people to come up with their own views and fight for them. The Nokia culture promotes intervention, contradiction, and difference of opinion. We respect people who are prepared to take risks and are not afraid to admit mistakes. At the same time, we admire people for being humble, no matter how great their accomplishments are." ${ }^{49}$

Innovation is inherently risky for both individuals and organizations, especially in the early phases when new ideas are generated and put into practice for the first time..$^{50}$ By definition, innovation is a novelty-producing process, consisting of a string of non-routine decisions made under uncertainty. ${ }^{51}$ The outcomes of an innovation cannot be known until they occur, making investing in new ideas a risky proposition for organizations. Individuals are aware of this risk and know they must respond accordingly. The outcome of their strategic response depends greatly on the balance of risks and rewards for innovating in that organization. Striking this balance is the key role of leaders of innovation.

Leaders must address both the organizational- and individual-level risks associated with innovation. At the organizational level, this means making sure that all employees are equipped to make sound strategic decisions and that they channel their creative energy toward domains that are strategically relevant. This clarity can be attained by exposing employees to customers' needs, and providing strategic information on a regular basis, including company goals for each client relationship.

Leaders play a critical role in informing organizational members about their guiding mission and providing up-to-date information regarding strategy, particularly as new problems arise. To do this, organizations must be structured in such a way that information can flow freely and transparently - this includes open vertical and lateral communication channels, as well as temporal ones. ${ }^{52}$ When innovation occurs quickly and is distributed throughout an organization, as it is in many service industries, it is useful for organizations to develop a technology to store and retrieve 
the rich history of discoveries and ideas (failed, successful, and unknown) that are gained each day. ${ }^{53}$ Companies such as Georgia Pacific, BristolMyers Squibb, and Unilever have all invested heavily in idea management systems that facilitate organizing, directing, and retrieving stored information related to potential innovation avenues. ${ }^{54}$

Informing employees about strategic objectives can help to decrease the organizational-level risks of innovating. However, knowing that one is informed is the key to decreasing employees' apprehension about the risks of innovation. ${ }^{55}$ Easing the personal risks associated with innovating requires that employees at all levels feel that they are accountable for the diligent pursuit of strategic goals rather than strictly to the outcomes, and that they are rewarded for well-conceived, strategically aligned innovation efforts rather than the absolute success of new ideas.

Leaders can instill this sense of confidence by engaging in frequent one-to-many interactions, such as those described by Jack Welch, former CEO of General Electric:

Everyone in a company should have something to say about values. Yes, that can be a messy undertaking. That's OK. In a small enterprise, everyone can be involved in debating them in all kinds of meetings. In a larger organization, it's a lot tougher. But you can use company-wide meetings, training sessions, and the like, for as much personal discussion as possible, and the intranet for broader input. Getting more participation really makes a difference, giving you more insights and more ideas, and at the end of the process, most importantly, much more extensive buy-in. ${ }^{56}$

Company-wide communications demonstrate that critical information is being shared consistently and transparently and that management is not afraid to stand by what is said. ${ }^{57}$

- Innovation in services balances risks and rewards. In addition to decreasing perceived risks, leaders can have a powerful impact on their organization's ability to innovate by increasing the rewards of innovating. However, those leaders who recognize that creatively solving problems to achieve goals is rewarding in itself (what creativity researchers describe as intrinsic motivation) will have a significant advantage over those who rely exclusively on extrinsic rewards like financial incentives and promotions.58 Simply put, people enjoy generating useful new ideas when they are not afraid of negative consequences and when they care about the problem they are trying to solve. People want to see their own ideas succeed. One of the challenges service industry leaders face in creating an innovative organization is ensuring that the rewards for innovative behavior outweigh the risks inherent in being creative. Developing new ideas challenges the status quo and can attract more intense scrutiny.59 Being credited as the originator of a highly successful idea can boost one's personal and professional reputation, but failure is common and is punished by many organizations.60 Unfortunately, the uncertain likelihood 
of success and significant repercussions of failure can easily overshadow the potential rewards for innovating.

One of the challenges service industry leaders face in creating an innovative organization is ensuring that the rewards for innovative behavior outweigh the risks inherent in being creative and breaking from the historical norm. We highlight two such risks: personal franchise risk and information risk.

The personal risks of innovating are especially salient in professional services, where careers are defined by the strength of one's personal franchise, including one's history of accomplishments, one's network, and one's client base. By the time executives have reached the Vice President or Managing Director level, they have invested years in developing a portfolio of deep and broad client relationships. Such relationships are the hallmark of many professional service businesses. They are also the hardearned foundation of service executives' personal revenue stream. For an executive to shift focus away from their personal franchise to take on a risky new innovation, while perhaps best for the organization, can be a significant opportunity cost.

However, leaders have compelling reasons to offset those personal career risks with other more secure incentives. Senior executives are in many ways ideal innovation champions. First, given typical promotion patterns in organizations, the customer expertise they have developed is essential to identifying user's unmet needs and "pain points" - the first step in innovative problem solving. Second, the executive's personal network of contacts (both inside and outside the firm) is required for garnering support and resources for implementing a new idea, and for using personal influence to convert skeptics into believers.

How can leaders temper the career risks faced by individuals who champion innovations and take on innovative projects? One technique is to keep a dotted-line reporting link to one's past manager so that if the new idea does not take off, one has a kind of career lifeline-an informed advocate for the transition into a subsequent role.

Furthermore, employees should feel safe making mistakes. ${ }^{61}$ A certain degree of failure is a necessary and valuable part of the innovation process. The outcome of a responsibly conceived new idea should not affect the consequences it brings for its originator. Employees should know that using information and coming up with creative ideas focused on achieving their company's goals is more important than the success of any single idea, since fear of failing could prevent good ideas from being considered. This means rewarding well-informed innovation efforts, even when the outcomes are less than optimal.

Decisions about innovative ideas are always made with incomplete information. However, waiting for all uncertainties to be resolved means taking the risk that competitors will move first. In a high-stakes game like investment banking, employees must be accountable for making 
well-informed decisions, but not for eliminating every source of ambiguity. Paradoxically, being confident that they have the same access to information as those around them significantly increases the likelihood that they will be willing to innovate when a new problem or opportunity arises, because they will know what degree of ambiguity to accept before implementing a new idea.

Confidence in the information guiding one's judgment enables all kinds of on-the-spot creative problem-solving decisions: What are the most important user needs to look for? What kinds of ideas are likely to produce results that address those needs? What old ideas are relevant to this new situation, and how can they be recombined or improved to solve the problem at hand? Who holds the information and resources to implement this idea?

Making sure that employees feel confident that they are wellinformed and aware of top strategic aims enables them to generate creative service ideas and helps them know how to judge which ideas are likely to be strategically useful. By being well informed, employees can attend to the most strategically relevant problems and opportunities. However, by knowing that they are well-informed, the perceived risks associated with making decisions about innovative ideas are drastically decreased. This confidence is what enables the most innovative professional service firms to evolve rapidly, by allowing fluid point-of-service innovation.

\section{Pitfalls: How Not to Develop and Sustain an Innovation Culture in Services}

In addition to considering the characteristics and practices that foster sustained innovation, the case study and discussion above point to a number of pitfalls that can arise from unconsidered application of ideas designed for innovation in physical products. These approaches, which may at first seem like useful frames for innovating, are ill-suited to the requirements for success in investment banking and in other service organizations. In other words, they will not sustain innovation. There are five such pitfalls:

- Pitfall \#1: The Innovation Squad-In physical product and technology industries, the task of innovating is typically assigned to a particular unit, such as R\&D or Product Development. Successful innovation in service business is more democratic and distributed, affecting the behavior-the product—of a much wider range of people. An approach to innovation in services that targets innovation culture to a particular group or groups misses the systemic nature of innovation in services. For example, in summarizing a recent survey of 765 CEOs conducted by IBM's Business Consulting Service group, Violino states, "Without a supportive corporate culture, proper funding for investment, and a cooperative workforce, even the best plans for innovation will falter." ${ }^{62}$ 
- Pitfall \#2: The Award Winners-Innovation in services tends to be game evolving, not game changing. It is less about radical wins from creating and dominating market segments. It is instead about incremental wins from fresh thinking that beats competitors for new deals and new customers at the margin. The award-winner stories that are so often discussed in the physical product and technology setting-3M's Post-It notes, Google, Apple's iPod-have led some service organizations to overemphasize radical innovation, the pot of gold. That distracts attention from where the innovation value is.

- Pitfall \#3: The Start-Up-It is common to view innovation as a major challenge for incumbents. ${ }^{63}$ The implication is that stand-alone, start-up operations are the place to innovate. If innovation must take place in the corporate setting, then a distinct structure needs to be created. ${ }^{64}$ This tension is significantly less in many service settings, precisely because innovation typically occurs as a culmination of increments.

- Pitfall \#4: The Sprint-In services, innovation is a marathon, not a sprint. It is about pace. If a firm consistently innovates at a rate just above its competitors, it will be peerless much of the time. Sprinting for big wins, given the rapid pace of commoditization faced by many service businesses, is unlikely to be fruitful both because it burns people out and because it does not contribute to a long-term view of regular and sustained innovation.

- Pitfall \#5: Leaderless Innovation-Innovation in physical products and high technology is typically analyzed with little reference to leadership and the importance of strong leadership in making innovation happen. Leaders play a fundamental role in enabling innovation in service industries. The cultural and organization foundations that must be in place to activate distributed innovation over long periods of time (and within a business model that is flexible enough to capitalize on the best opportunities) are complex and distinct from those outside of services. The lack of guidance many service business leaders are finding in the existing innovation literature is testimony to this.

\section{Leadership Implications}

What is different about leading through innovation, as opposed to simply leading people? There are various things leaders must do if they are to succeed at service innovation: leverage organizational structures and processes to build a culture of innovation, carefully attend to formal and informal incentives, open flows of information, and manage the perception of risk around innovating. However, it is equally important to emphasize what leaders of service innovation must not do.

When constant innovation is not a survival imperative, leaders can afford to focus their organization's culture, structure, and incentives on increasing returns on existing products and services. For the bulk of the organization, relia- 
bility and efficiency in achieving the leader's vision are preferred to creativity and pervasive change. A leader's role is one of creating a vision-setting a clear direction and inspiring the organization to achieve it. ${ }^{65}$ Strategic shifts in this setting are broad and intermittent, their execution decisively planned at the top by a team of top executives. The leader's job is to align all resources to achieve this vision, motivating employees to consistently execute their roles with a focus on realizing that vision of the future.

Leading through innovation, however, is not about selling a grand strategic vision or steering the organization towards its execution. Leading through innovation means allowing the vision to emerge from throughout the organization-watching for insights and clues to the ever-changing needs and demands of clients as they bubble up. Leaders must be problem-oriented, leveraging all of their employee's client knowledge and creativity to find the problems with unknown solutions and to solve them. It will be clear to all stakeholders and employees in an innovative service firm that the leader's loyalty lays with the clients and their problems and needs, rather than with a tried-and-true solution.

Leading through innovation is not about leading people toward one's own vision, innovative though it may be. Leading through innovation is about allowing and enabling people to continually create and deliver small innovations every day. The competition will not wait for a cumbersome, multi-layered approval process. In service innovation, the time for preventing mistakes is not between idea generation and delivery to the customer. To enable fast and fluid innovation in an intimate client-customer relationship, leaders must prepare, provide resources, trust their people, and let go. This means hiring the right people, giving them access to the best information and tools, and assuring them that they are well equipped - that they know what needs to be known. Then give them the latitude to do their jobs-potentially in a different way each day-to serve that one end goal: solving the customer's problems today, whatever they may be.

\section{Conclusion}

Increasingly one hears leaders assert that they compete on innovation, meaning that innovation is the fundamental basis of competition in their business. These leaders hail from a wide range of industries. Competing on innovation in services is different than competing on innovation in physical products or high technology. In particular, innovation in services is relatively: distributed throughout the organization; fluid, that is, more continuous than discrete; broadly relevant to hiring and promotion decisions; influenced by reward systems and culture at the firm-wide level; and enabled by leadership. When behavior itself is the product, the cultural and organizational foundations that guide that behavior are essential for competing on innovation effectively. Unconsidered application in services of ideas designed for innovation in physical products leads to many pitfalls. 


\section{Notes}

1. Central Intelligence Agency, The World Factbook, 2007.

2. Organization for Economic Cooperation and Development, Economic Outlook, 2005.

3. International Monetary Fund, World Economic Outlook, 2006.

4. For example, compensation to marketmakers in financial products. New York Stock Exchange, Facts and Figures, <www.nysedata.com/nysedata/Home/FactsFigures/tabid/115/ Default.aspx>, 2007.

5. Rosabeth Moss Kanter, "When a Thousand Flowers Bloom: Structural, Collective, and Social Conditions for Innovation in Organizations," in Research in Organizational Behavior, 10 (1988): 169-112; M.A. West, "Sparkling Fountains or Stagnant Ponds: An Integrative Model of Creativity and Innovation Implementation in Work Groups," Applied Psychology: An International Review, 51/3 (2002): 355-424.

6. Yahoo Finance Industries Webpage, <http://biz.yahoo.com/ic/>, 2007.

7. See, for example, Charles A. O'Reilly and Jennifer A. Chatman, "Culture as Social Control: Corporations, Cults, and Commitment," Research in Organizational Behavior, 18 (1996): 157200.

8. John P. Kotter, John P. Kotter on What Leaders Really Do (Boston, MA: Harvard Business School Press, 1999).

9. Business Week, June 19, 2006, p. 28

10. See, for example, C.M. Christiensen, The Innovator's Dilemma: When New Technologies Cause Great Firms to Fall (Boston, MA: Harvard Business School Press, 1997); G. Hamel, Leading the Revolution (New York, NY: Plume, 2002); A. Hargadon, How Breakthroughs Happen: The Surprising Truth about How Companies Innovate (Cambridge, MA: Harvard Business School Press, 2003).

11. L.L. Berry, S. Venkatesh, J.T. Parish, S. Cadwallader, and T. Dotzel, “Creating New Markets Through Service Innovation," MIT Sloan Management Review, 47/2 (Winter 2006): 56-63.

12. B.H. Hall, "Business Method Patents, Innovation, and Policy," National Bureau of Economic Research (NBER) working paper, 2003.

13. Ken MacFadyen, "Open-Source Finance," Investment Dealers Digest, February 26, 2007, pp. 4, 11 .

14. R. Brealey, S. Myers, and F. Allen, Principles of Corporate Finance, 8th edition (New York, NY: McGraw Hill, 2005).

15. S.E. Ante and C. Edwards, "The Science of Desire: As more companies refocus squarely on the consumer, ehtnography and its composents have become star players," Business Week, June 5, 2006.

16. Y. Doz, K. Wilson, S. Veldhoen, T. Goldbrunner, and G. Altman, "Innovation: Is Global the Way Forward? Survey Results," INSEAD and Booz-Allen Hamilton, 2006.

17. Goldman Sachs, Annual Report, 2006.

18. Natalie Shope Griffin, "Personalize Your Management Development," Harvard Business Review, 81/3 (March 2003): 113-119.

19. E. Mannix, and M.A. Neale, "What Differences Make a Difference?" Psychological Science in the Public Interest, 6/2 (October 2005): 31-55.

20. A.W. Ulwich, What Customers Want: Using Outcome-Driven Innovation to Create Breakthrough Products and Services (New York, NY: McGraw-Hill, 2005).

21. E. Von Hippel, The Democratization of Innovation (Cambridge, MA: MIT Press, 2005).

22. See, for example, J.L. Martin, Organizational Culture: Mapping the Terrain (Thousand Oaks, CA: Sage Publications, 2002).

23. See, for example, T.M. Amabile, Creativity in Context (Boulder, CO: Westview Press 1996), p. 317.

24. See, for example, N. King and N. Anderson, "Innovation and creativity in working groups," in M.A. West and J.L. Farr, eds., Innovation and Creativity at Work: Psychological and Organizational Strategies (New York, NY: Wiley, 1990), pp. 81-100.

25. C.A. O'Reilly III and J.A. Chatman, "Culture as Social Control: Corporations, Cults, and Commitment," in B. Staw and L. Cummings, eds., Research in Organizational Behavior, 18 (1996): 157-200.

26. Michael L. Tushman and Charles A. O'Reilly III, "The Ambidextrous Organization," Harvard Business Review, 82/4 (April 2004): 74-81.

27. See, for example, J.A. Chatman and S.G. Barsade, "Personality, Organizational Culture, and Cooperation: Evidence from a Business Simulation," Administrative Science Quarterly, 40/3 
(September 1995): 423-443; P.C. Earley, “East Meets West Meets Mideast: Further Explorations of Collectivistic and Individualistic Work Groups," Academy of Management Journal, 36/2 (April 1993): 319-348.

28. See, for example, J.A. Chatman, J.T. Polzer, S.G. Barsade, and M.A. Neale, “Being Different yet Feeling Similar: The Influence of Demographic Composition and Organizational Culture on Work Processes and Outcomes," 43/4 (December 1998): 749-780.

29. T.M. Amabile, R. Conti, H. Coon, J. Lazenby, and M. Herron, "Assessing the Work Environment for Creativity," Academy of Management Journal, 39/5 (1996): 1154-1184.

30. J.B. Sorensen, "The Strength of Corporate Culture and the Reliability of Firm Performance," Administrative Science Quarterly, 47/1 (March 2002): 70-91.

31. C.J. Nemeth and B.M. Staw, "The Tradeoffs of Social Control and Innovation in Groups and Organizations," in L. Berkowitz, ed., Advances in Experimental Social Psychology, Volume 22 (San Diego, CA: Academic Press, 1989), pp. 175-210.

32. Ibid., p. 175.

33. J.A. Chatman and F.J. Flynn, “The Influence of Demographic Heterogeneity on the Emergence and Consequences of Cooperative Norms in Work Teams," Academy of Management Journal, 44/5 (October 2001): 956-974.

34. O'Reilly and Chatman, op. cit.

35. S. Thomke and A. Nimgade, "Innovation at 3M Corp. (A)," Harvard Business School Case \#9699012, 2002).

36. C.A. O'Reilly III and J. Pfeffer, "Southwest Airlines (A)," Stanford University Case (available through Harvard Business School Publishing), 1995.

37. G.A. Cole, Management: Theory and Practice, 5th Edition (London: DP Publications, 1999).

38. D. Packard, The HP Way: How Bill Hewlett and I Built our Company (New York, NY: Harper Business, 1995).

39. "Information Technology: Managing Google's Idea Factory: Marissa Mayer helps the search giant out-think its rivals," Business Week, October 3, 2005.

40. M.L. Tushman and C.A. O'Reilly III, Winning through Innovation (Cambridge, MA: Harvard Business School Press, 1997).

41. J.A. Chatman, "Matching People and Organizations: Selection and Socialization in Public Accounting Firms," Administrative Science Quarterly, 36/3 (September 1991): 459; E.W. Morrison, "Longitudinal Study of the Effects of Information Seeking on Newcomer Socialization," Journal of Applied Psychology, 78/2 (1993): 173-183.

42. C.A. Bartlett, B.J. Hall, and N. Bennett, "GE's Imagination Breakthroughs: The Evo Project," Harvard Business School Case \#9907048, 2007.

43. Ibid.

44. B. Violino, "Top-Down Innovation," Optimize, 5/5 (May 2006): 61.

45. Ibid.

46. See, for example, K.A. Jehn and E.A. Mannix, "The Dynamic Nature of Conflict: A Longitudinal Study of Intragroup Conflict and Group Performance," Academy of Management Journal, 44/2 (April 2001): 238-251.

47. A. Grove, Only the Paranoid Survive (New York, NY: Doubleday, 1996).

48. D. Bunnell, The E-Bay Phenomenon: Business Secrets Behind the World's Hottest Internet Company (New York, NY: John Wiley and Sons, 2001), p. 100.

49. J. Blau, "At Nokia temperament Is a Core Competence (Corporate Strategy)," ResearchTechnology Management, 46/4 (July 2003): 6.

50. T. Dewett, "Exploring the Role of Risk in Employee Creativity," Journal of Creative Behavior, 40/1 (2006): 27-45.

51. H. Heerkens, “Assessing the Importance of Factors Determining Decision-Making by Actors Involved in Innovation Processes," Creativity and Innovation Management, 15/4 (2006): 385 399.

52. Tushman and O'Reilly, op. cit.

53. N.M. Mostert and H.J.B. Slot, "Creativity, The Knowledge Connector," in M. Rao, ed., Knowledge Management Tools and Techniques: Practitioners and Experts Evaluate KM Solutions (Boston, MA: Elsevier, 2004).

54. M.K. McGee, "Georgia-Pacific Uses Innovation Brainstorming Tool," InformationWeek, March 23, 2005.

55. Tushman and O'Reilly, op. cit.

56. J. Welch and S. Welch, Winning (New York, NY: HarperBusiness, 2006). 
57. S. Cha and A. Edmondson, "How Values Backfire: Leadership, Attribution and Disenchantment in a Values-Driven Organization," Leadership Quarterly, 17/1 (2006): 57-78.

58. M.A. Collins and T.M. Amabile, "Motivation and Creativity," in R.J. Sternberg, ed., Handbook of Creativity (Cambridge, UK: Cambridge University Press, 1999); R. Eisenberger and J. Cameron, "Detrimental Effects of Reward: Reality or Myth?" American Psychologist, 51/11 (1996): 1153-1166.

59. J. Pfeffer and R.I. Sutton, The Knowing-Doing Gap: How Smart Companies Turn Knowledge into Action (Boston, MA: Harvard Business School Press, 2000).

60. T.M. Amabile, S.G. Barsade, J.S. Mueller, and B.M. Staw, "Affect and Creativity at Work," Administrative Science Quarterly, 50/3 (September 2005): 367-403.

61. D.F. Caldwell, and C.A. O'Reilly III, “The Determinants of Team-Based Innovation in Organizations: The Role of Social Influence," Small Group Research, 34/4 (2003): 497-517; A. Edmondson, "Psychological Safety and Learning Behavior in Work Teams," Administrative Science Quarterly, 44/2 (June 1999): 350-383.

62. Violino, op. cit.

63. Christiensen, op. cit.

64. C.A. O'Reilly III and M.L. Tushman, "The Ambidextrous Organization," Harvard Business Review, 82/4 (April 2004): 74-81.

65. Kotter, op. cit. 
Copyright of California Management Review is the property of California Management Review and its content may not be copied or emailed to multiple sites or posted to a listserv without the copyright holder's express written permission. However, users may print, download, or email articles for individual use. 